\title{
A "viagem de volta":* significados da pesquisa na formação e prática profissional do Assistente Social
}

\section{The "return": mean of research both in the training and in the professional practice in Social Work}

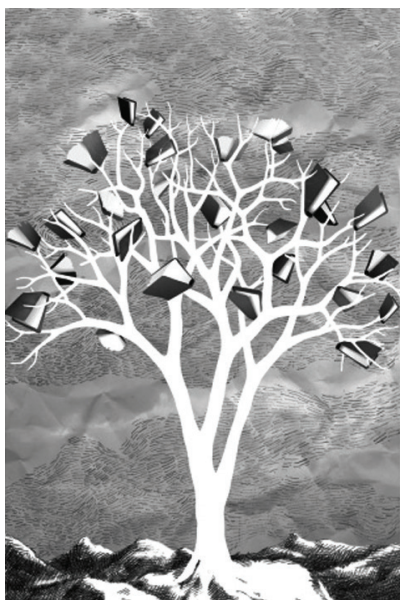

Carlos Antonio de Souza Moraes**

Resumo: O artigo discute a pesquisa na formação e prática profissional. No primeiro momento, realiza uma descrição histórica referente à pesquisa e produção do conhecimento no Serviço Social, buscando identificar as "mudanças" ético-política e teórico-metodológica vivenciadas pela disciplina de pesquisa. Em seguida, problematiza a relação da pesquisa com a prática profissional do Serviço Social na atualidade. Por fim, indica a necessidade de se aprofundar essa discussão a partir de um mergulho analítico e atual referente às principais tendências da sociedade capitalista e suas repercussões no campo da pesquisa na formação e prática profissional em Serviço Social.

Palavras-chave: Pesquisa. Serviço Social. Prática profissional. Formação profissional.

* O título ("A viagem de volta”) e seus desdobramentos são frutos de indicações detectadas por Marilda Iamamoto no livro Serviço Social em tempo de capital fetiche. Nele, a autora identifica que o tema referente à formação profissional em Serviço Social (fundamentos e exercícios da profissão) não alcança o merecido destaque na pós-graduação strictu sensu em Serviço Social.

Apesar de avanços concernentes à discussão, que permitiram romper com qualquer endogenia na leitura da profissão, "parece ainda ser necessária realizar a 'viagem de volta' para apreensão do exercício e da formação profissionais em suas múltiplas determinações e relações no cenário atual". Neste caso, é necessário identificar, extrair e analisar as incidências da dinâmica societária (relações e contradições sociais) "nos fundamentos e processamento de trabalho profissional, retomando, [...] sob novas luzes, o Serviço Social" (Iamamoto, 2008, p. 44).

** Mestre em Políticas Sociais pela Universidade Estadual do Norte Fluminense; doutorando em Serviço Social pela PUC/SP-Brasil; membro do Grupo Interdisciplinar de Estudos e Pesquisa em Cotidiano e Saúde (Gripes); professor assistente do departamento de Serviço Social de Campos/Universidade Federal Fluminense — Rio de Janeiro, Brasil.E-mail: as.carlosmoraes@gmail.com. 


\begin{abstract}
The article discusses research on training and professional practice. At first, performs a historical overview on the research and production of knowledge in social work, seeking to identify the "changes" ethical-political and theoretical and methodological experienced by research discipline. Then discusses the relationship of research to professional practice of social work today, identifying some of its main directions. Defend the meaning of knowledge production as "a constitutive element of professional action" (Nogueira, 2010, p. 1). Finally, it indicates the need to deepen this discussion from a dive and current analytical regarding the main trends of capitalist society and its impact on research in the field of training and professional practice in Social Work.
\end{abstract}

Keywords: Research. Social Services. Professional practice. Training.

\title{
I. Introdução
}

A rigor, cada viajante abre seu caminho, não só quando desbrava o desconhecido, mas inclusive quando redesenha o conhecido. (Ianni, 2000, apud Bourguignon, 2005, p. 10)

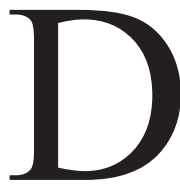

ebates em torno de pesquisa e intervenção são conhecidos no Serviço Social, sobretudo, a partir da configuração das últimas "diretrizes gerais para o curso de Serviço Social", em que a pesquisa é proposta como princípio e condição da formação profissional. Portanto, a formação permanente de uma postura investigativa deve ser inerente a todo o processo de formação profissional.

Isto significa que o Serviço Social, a partir de sua organização acadêmico-política, tem se preocupado em formar profissionais capazes de realizar pesquisas que subsidiem a formulação de políticas e ações profissionais.

Assim, o pressuposto é de que a pesquisa deva consistir em um rigoroso trato teórico, histórico e metodológico da realidade social e do Serviço Social, de maneira que se construa a compreensão dos problemas sociais e os desafios do universo da produção e reprodução da vida social (Pastor e Marques, 2010).

Essas preocupações no campo profissional têm demonstrado, segundo Bourguignon (2008), avanços quanto às consistências das produções acadêmicas no âmbito das ciências sociais aplicadas. Por outro lado, alguns desafios se colocam e ampliam na formação e exercício da pesquisa no Serviço Social. Tais desafios estão, sobretudo, direcionados para as unidades de ensino no Brasil e aos assistentes sociais.

De maneira geral, são precárias as condições objetivas para o enfrentamento desses desafios e o cumprimento dessas exigências. Em relação às unidades de 
ensino, é possível perceber os impactos das políticas neoliberais do Estado brasileiro na redução de recursos para as atividades de pesquisa, na ampliação das universidades públicas sem investimento na qualidade do ensino, da pesquisa e extensão, na privatização interna dessas universidades, comprometendo sua autonomia e gestão democrática, no aumento dos cursos de graduação à distância, além do crescimento de universidades particulares sem compromisso com a qualidade do ensino e sem preocupação com a implementação de atividades de pesquisa e extensão, entre outros fatores.

Em relação aos profissionais de Serviço Social, é possível identificar, não raras vezes, que o discurso de valorização da pesquisa nem sempre alcança a prática. As justificativas são muitas: falta de tempo, excesso de atribuições, pouca disponibilidade de pessoal, ausência de recursos... Mesmo com essas restrições, nos deparamos com situações em que a pesquisa é incorporada ao trabalho do profissional, sobretudo por motivo de cursos de especializações. Nesses casos, é vinculada a ideia de que a pesquisa está estritamente relacionada a normas, prazos e obrigações a ser cumpridas, aprisionando uma prática que deveria ter ousadia, desafiar, investigar e gerar prazer com as novas descobertas e possibilidades de ação (Moraes, Juncá e Santos, 2010).

Diante disso, é possível perceber que, apesar de o Serviço Social plasmar a centralidade da pesquisa na formação e no exercício profissional, existem desafios que precisam ser enfrentados no âmbito acadêmico e no exercício profissional. Desafios que tem descaracterizado a universidade brasileira enquanto instituição pública a serviço da população e tem contribuído para que a pesquisa não seja construída com as projeções desejadas na prática profissional, o que pode estar comprometendo a construção da criticidade no cotidiano de trabalho e, consequentemente, a capacidade de desvelamento das contradições estruturais, bem como o trabalho em apoio às classes subalternas.

Diante desses indicativos e do reconhecimento da particularidade da pesquisa no Serviço Social, este artigo tem por objetivos identificar a trajetória da pesquisa como tema e disciplina na formação profissional do Serviço Social, bem como discutir elementos que afirmam em que sentido(s) a pesquisa subsidia o exercício da profissão na contemporaneidade.

Para atingir tais objetivos, este artigo de revisão foi construído a partir de leitura e análise de livros, teses e outros artigos publicados em revistas científicas, bem como nos encontros e congressos de pesquisa em Serviço Social que discutem 
o tema em questão. Nesses materiais, foi possível identificar a construção de uma política de pesquisa em contextos particulares (na Universidade Federal do Maranhão, por exemplo, por meio de estudo realizado por Brandão, 2010) ou no cenário brasileiro de maneira geral (por meio de discussões travadas por autores como: Sposati, 2007; Bourguignon, 2008; Nogueira, 2010, entre outros).

Ao reunir de forma complementar essas discussões e construir uma série de problematizações tendo por base as transformações sociopolíticas da sociedade brasileira na era de mundialização do capital, este artigo demonstra sua relevância científica e originalidade. Esta última pode ser identificada na medida em que essas discussões nem sempre são travadas em conjunto pela bibliografia pesquisada (apesar de demonstrarem que se complementam): ora se privilegiam os sentidos da pesquisa na formação profissional, ora na prática profissional.

Por outro lado, é possível destacar sua relevância social a partir de possíveis contribuições para o encaminhamento da pesquisa nos espaços acadêmicos e profissionais de maneira geral.

Diante disso, a proposta ora descrita se subdivide em dois momentos centrais: no primeiro, serão descritos e compreendidos, de maneira ampliada, os aspectos históricos relacionados à pesquisa e à formação profissional em Serviço Social, para em seguida (segundo momento) problematizar seus sentidos vinculados à prática profissional na atualidade. Além disso, serão apontadas algumas indicações finais com base no que foi discutido ao longo do corpo do trabalho, bem como apresentadas questões que avaliamos ser importantes para o desenvolvimento de eventuais estudos que tenham por objetivo mapear o "estado da arte" na pesquisa no Serviço Social.

\section{Trajetória da pesquisa como tema e disciplina na formação profissional do Serviço Social}

Este item aborda a produção do conhecimento em Serviço Social a partir de uma dupla relação: com a profissão e com a formação profissional. ${ }^{1}$ A partir de uma

1. Na presente análise, em conformidade com Cardoso (1998), compreende-se a formação profissional do assistente social como um amplo processo determinado socialmente, de um lado pelas relações mais gerais 
abordagem histórica, serão identificadas as "mudanças" ético-política e teórico-metodológica vivenciadas pela disciplina de pesquisa. Além disso, há aqui a defesa do significado da produção de conhecimento como "elemento constitutivo da ação profissional" (Nogueira, 2010, p. 1).

A preocupação com a pesquisa/dimensão investigativa/produção de conhecimento deve ser antecedida por uma apreensão de seu real significado para a profissão que tem razão de ser na intervenção. No entanto, o papel, a "funcionalidade da pesquisa no exercício profissional", bem como, seu trato na formação, "são distintos na trajetória do Serviço Social, variando a centralidade dos objetos de estudo e os métodos para sua análise" (Nogueira, 2010, p. 3).

É sabido (Yazbek, 2004; Martinelli, 2009; Iamamoto, 1982; Ortiz, 2010) que, no Brasil, a origem do Serviço Social está localizada em um complexo quadro conjuntural que caracterizava o país naquele momento. Isto é, na emergente sociedade urbana industrial (anos 1930), em uma conjuntura peculiar do desenvolvimento capitalista, marcada pelo movimento do operariado e seu amadurecimento político (conflitos de classe) em suas lutas contra exploração do trabalho e defesa dos direitos de cidadania (Yazbek, Raichelis e Martinelli, 2008).

Nesse cenário, o Serviço Social se gesta e desenvolve a partir de requisições do Estado (que legitima e enquadra juridicamente a "questão social") e da classe dominante como um de seus recursos (com suporte da Igreja católica) na perspectiva de regulação e enfrentamento da "questão social". Esta que é matéria-prima do Serviço Social e justifica sua constituição na divisão sociotécnica do trabalho (Martinelli, 2009).

Sob influência da Igreja católica e/ou a partir de uma mesclagem entre as visões francesas e belga, o Serviço Social inicia um trabalho fundamentado em suas perspectivas ética, social e técnica da formação profissional. Trabalho que voltava para adaptação do indivíduo ao meio e do meio ao indivíduo, na perspectiva de restaurar e normalizar a vida social. Sua contribuição incidia sob valores e comportamentos de seus "clientes" na busca de sua integração às relações sociais

\footnotetext{
de determinada formação social e, de outro, pela universidade enquanto instituição diretamente responsável pela formação básica do profissional. Assim definida, a formação profissional é um projeto complexo que inclui na sua estrutura, além do ensino acadêmico, da graduação e pós-graduação, a capacitação de profissionais docentes e não docentes, a prática profissional e organizativa e a pesquisa como importante instrumento na definição e redefinição desse projeto.
} 
vigentes. Tratava-se de um enfoque psicologizante e moralizador da "questão social”, centrado no indivíduo e na família.

A esse respeito Martinelli (2009) identifica que as práticas do Serviço Social expressavam-se como um mecanismo de reprodução das relações sociais de produção capitalista - como estratégia de garantir a expansão do capital, ou seja, uma identidade que era atribuída pela classe dominante e pelo Estado no desenvolvimento de seu trabalho concreto, dotado de qualidade determinada (Iamamoto, 2008).

A partir da década de 1940 há a criação e o desenvolvimento de instituições assistenciais estatais, que amplia o mercado de trabalho do Serviço Social e diversifica o perfil dos profissionais, visto que aumentavam os interesses particulares (qualificação, melhores salários...) na escolha da profissão (Martinelli, 2009).

Nesse processo, o Serviço Social vai se aproximar da abordagem norte-americana, articulando-a ao conservadorismo católico, o que Iamamoto (2008) vai denominar de "arranjo teórico doutrinário".

Martinelli (2009) ressalta que, nesse período, os assistentes sociais estavam apossados pelo "fetiche da prática", por meio de um agir imediato, espontâneo, alienado e alienante, roubando qualquer possibilidade de reflexão e crítica, o que fortalecia a "identidade atribuída" da profissão.

Particularmente, a orientação funcionalista é absorvida pelo Serviço Social, configurando propostas de trabalho ajustadoras e um perfil manipulatório, voltado para o aperfeiçoamento dos instrumentos e técnicas para a intervenção, com as metodologias de ação, busca de eficiência, sofisticação dos modelos de análise, diagnóstico e planejamento, enfim, uma tecnificação da ação profissional que é acompanhada de crescente burocratização das atividades institucionais. Essa perspectiva busca ajuste e conservação em relação aos sujeitos na ordem estabelecida (Yazbek, 2009). Nesse sentido, o Serviço Social assume a execução de políticas sociais, o que lhe proporciona, por intermédio do Estado, a profissionalização e da ampliação do mercado de trabalho.

Assim, com base na natureza eminentemente interventiva da profissão nesse período, a Lei n. 1.889/53 define os objetivos do ensino do Serviço Social, a partir do estudo de disciplinas organizadas, segundo Nogueira (2010, p. 3), em três eixos:

I - eixo do conhecimento da realidade social, econômica, psicológica e ética geral e profissional; 
II — eixo da introdução e dos fundamentos do Serviço Social: Métodos do Serviço Social; Serviço Social de Casos - de Grupo - Organização Social da Comunidade: Serviço Social em suas especializações; Família — Menores — Trabalho — Médico; III — o eixo da Pesquisa Social.

Além disso, a autora ressalta que o programa de pesquisa social estava destinado, com base em procedimentos da pesquisa científica, a subsidiar a intervenção. Sua ementa continha os seguintes itens:

conceituação [da pesquisa social], sua posição face às Ciências Sociais, relações com o Serviço Social, problemática da pesquisa, peculiaridades, condições que afetam a objetividade, condições ambientais e condições do pesquisador e do pesquisado; métodos indutivo e dedutivo, método estatístico, geográfico e sociológico, antropológico; observação em massa e participante, método comparativo e experimental. (Nogueira, 2010, p. 3)

Diante dessa ementa, torna-se perceptível a preocupação da disciplina em subsidiar a intervenção a partir de procedimentos de pesquisa científica, tendo por foco a apropriação positiva da realidade, com objetivo de, por meio do método científico, obter informações para a intervenção. "A preocupação com a cientificidade se manifestava na ênfase dos procedimentos metodológicos quanto ao trato da empiria, e reduzíssima ênfase na perspectiva analítica" (Nogueira, 2010, p. 4).

Nesse contexto (década de 1950-60), o Serviço Social, ao possuir relativa autonomia técnica e sendo legalmente reconhecido, tem, segundo Martinelli (2009), um salto quantitativo e qualitativo por meio do aumento no número de escolas; interiorização para as prefeituras de cidades pequenas e médias; abertura para o campo industrial; incorporação de novas funções, como coordenação, planejamento e administração de programas sociais, o que revelava o alcance de maior sistematização teórica e prática.

Na subsequente revisão curricular (realizada em 1962), Nogueira (2010) destaca que o ensino da pesquisa manteve a direção anterior. Posteriormente, em virtude da realidade brasileira e da hegemonia do pensamento sociológico norte-americano, a pesquisa realizada pelo Serviço Social passou a contribuir de maneira significativa para o protagonismo e o reconhecimento profissional, ao evidenciar as situações de pobreza e marginalização de grupos e segmentos populacionais e servir para o direcionamento de ações institucionais. 
Por outro lado, a reforma universitária realizada em 1968 e implementada por grupos e setores que buscavam a consolidação do modelo desenvolvimentista, focados na formação de sujeitos para o mercado de trabalho, traduziu graves consequências para o ensino superior no Brasil.

No Serviço Social, conforme indica Setúbal (2007), pela primeira vez, a pesquisa é excluída do currículo da graduação como uma disciplina, sendo substituída pela "atitude investigativa", relacionada estritamente à extensão universitária e consolidando o saber resgatado do fazer como critério para a eficiência e produtividade. (Nogueira, 2010, p. 4)

Diante deste quadro de reforma, é possível identificar que nesse período, houve a ampliação da rede de serviços sociais, o que conduziu a profissão a um efetivo avanço nas esferas acadêmicas, organizativa e institucional, nos âmbitos público e privado.

Isso contribuiu para que a profissão questionasse seus referenciais e assumisse inquietações e insatisfações de uma conjuntura histórica de intenso movimento político-cultural que reuniu profissionais, trabalhadores, segmentos médios e das classes populares em torno da luta anti-imperialista na defesa de projetos de transformação social (Yazbek, Raichelis e Martinelli, 2008).

Nesse contexto, desencadeia na América Latina um amplo movimento de renovação profissional em diferentes níveis - teórico, metodológico, técnico/ operativo e ideopolítico - o qual impõe ao Serviço Social a necessidade de negar o aparente e, mais que isso, construir um projeto profissional comprometido com as demandas e interesses dos trabalhadores e das camadas populares, usuárias das políticas sociais.

Segundo Netto (2001), no bojo desse movimento e em seus desdobramentos históricos, são definidas e confrontadas diferentes tendências que incidiram em seus fundamentos teóricos e metodológicos e na direção social de sua intervenção. Este autor ressalta as seguintes vertentes de análise:

1) Vertente modernizadora: caracterizada pela incorporação de abordagens funcionalistas, estruturalistas, e mais tarde, sistêmicas (matriz positivista), voltadas para uma modernização do desenvolvimento social e do enfrentamento da marginalidade e da pobreza na perspectiva de integração da sociedade.

2) Vertente inspirada na fenomenologia: dirige-se ao vivido humano, aos sujeitos em suas vivências, colocando para o Serviço Social a tarefa de auxiliar na 
abertura desse sujeito existente, singular, em relação aos outros, ao mundo das pessoas. Nessa tendência, o Serviço Social brasileiro vai priorizar as concepções de pessoa, diálogo e transformação social (dos sujeitos). Ela é analisada por Netto (2001) como uma forma de reatualização do conservadorismo presente no pensamento inicial da profissão.

3) A vertente marxista: remete à profissão a consciência de sua inserção na sociedade de classes e que no Brasil se configura no primeiro momento em um marxismo sem Marx.

No curso desse movimento, o profissional passa a buscar paulatinamente a compreensão da análise e contradição como princípio explicativo do real. Além disso, passa a perceber o caráter conservador de sua prática, o que não aconteceu de forma homogênea.

Diante disso, é possível ressaltar que a consciência crítica colocava a necessidade de luta por novas superações dialéticas, pela consciência política da categoria, pela ampliação de espaços de produção do novo. Isto é, buscou-se criar uma proposta de profissão identificada com as classes populares.

Segundo Martinelli (2009) a partir de 1970-80 tornou-se possível identificar a categoria como um grupo portador de um projeto profissional comum. A identidade profissional passou a ser construída de maneira incessante e coletiva, como força viva. A prática profissional e política passou a estabelecer alianças com a classe trabalhadora.

Ainda na década de 1970, concomitante ao movimento de reconceituação do Serviço Social, é possível destacar um avanço na produção teórica da profissão no país, a partir da criação e expansão de cursos de pós-graduação, enquanto elemento fundamental para produção de bibliografias consistentes e continuadas do Serviço Social (Kameyama, 1998; Iamamoto, 1998; Pastor e Marques, 2010).

Durante esse processo, a Abess encaminha uma revisão curricular iniciada em meados dos anos 1970 e aprovada em 1979 em Natal e pelo MEC, em 1982 (Brandão, 2010). Esse novo currículo assinala um rompimento com a tradição teórica discutida e implementada nos currículos anteriores, que influenciava a construção do fazer e a formação profissional até então. Em relação à pesquisa, essa nova apreensão da profissão apresenta, segundo Nogueira (2010), dois vetores: 1) a relação intrínseca entre prática profissional e produção do conhecimento, isto é, a relação teoria e prática ainda não trabalhada de forma unitária; 2) a introdução de uma perspectiva crítica de análise na construção do saber profissional. 
A aprovação dessa proposta curricular (de maneira geral) foi uma vitória da luta coletiva da Abess, inclusive com a disciplina de pesquisa que, conforme Sposati (2007), passa a ser obrigatória na formação dos assistentes sociais a partir de 1982. Nesse contexto, Nogueira (2010) destaca alguns elementos para análise do papel da pesquisa na formação profissional:

1) a preocupação com a produção de conhecimento de forma mais sistemática, a partir da integração de cursos confessionais de Serviço Social para o espaço universitário federal. Além da interlocução da profissão com o campo das ciências sociais e a realização de encontros de pesquisa em âmbito nacional;

2) a inclusão do Serviço Social como área de conhecimento nas agências de financiamento (Capes, CNPq etc.), conferindo-lhe status acadêmico;

3) a criação do Centro de Documentação e Pesquisa em Políticas Sociais e Serviço Social (Cedepss), órgão acadêmico vinculado à Abess (que em 1998 passa a se chamar Associação Brasileira de Ensino e Pesquisa em Serviço Social - Abepss). Sua criação tinha por objetivo incentivar e estimular a construção de pesquisas nesta área, bem como documentar tais produções;

4) o conhecimento produzido até esse período histórico referenciava os elementos vinculados exclusivamente à ação profissional, não trabalhando com análises de realidade com base em um quadro explicativo mais denso.

Desta situação deriva um aspecto delicado para a relação entre a pesquisa/ profissão/formação profissional. Na medida em a prática conservadora foi sendo desqualificada, com toda a razão, não se investiu em análises sobre o fazer profissional e nem se gestaram formas inovadoras de ação profissional, compatíveis com o perfil estabelecido pelo novo currículo, sendo a preocupação maior, entre os docentes/pesquisadores, se apropriar do novo marco teórico indicado pelo currículo de 1982. (Nogueira, 2010, p. 5)

A esse respeito, convém recordar que a partir da década de 1980-90 é destacado o protagonismo do Serviço Social crítico. Ou seja, a teoria social de Marx passa a ser articulada de maneira mais efetiva com a profissão, por intermédio, inicialmente, das análises de Iamamoto em 1982 no livro Relações sociais e Serviço Social no Brasil, teoria que apreende o ser social a partir de mediações. Portanto, os fatos e 
dados passam a ser vistos como indicadores, e não como fundamentos do horizonte analítico. Isto é, as relações sociais são sempre mediatizadas por situações, instituições que ao mesmo tempo revelam/ocultam as relações sociais imediatas.

Trata-se, portanto, de um conhecimento que apreende a realidade de forma dialética em seu movimento contraditório. Movimento em que se engendram como totalidade as relações sociais que configuram a sociedade capitalista (Yazbek, Raichelis e Martinelli, 2008).

Esse referencial ganha visibilidade e imprime nova qualidade ao processo de recriação da profissão, além de ser substancial na busca de avanços na produção do conhecimento e no rompimento com o histórico conservadorismo no campo profissional.

Portanto, o Serviço Social brasileiro, nesse período, passa por um processo de maturação, rompendo com seu conservadorismo, embora não o tenha superado como lembra Netto (2001).

Assim, o Serviço Social também passa a assumir novas posições no mercado de trabalho, destacando-se o fato de desenvolver ações de planejamento e gestão de políticas sociais. No entanto, essas políticas sociais passam por um reordenamento, tornando-se cada vez mais seletivas e focalizadas. Além disso, há o apelo por parte da opção neoliberal, pela filantropia e à solidariedade da sociedade civil, o que traz novas questões ao Serviço Social do ponto de vista interventivo e da construção de seu corpo de conhecimentos.

Essa profissão, na década de 1990, se vê desafiada a compreender e intervir nas novas configurações e manifestações da "questão social", visto que há o aprofundamento da precarização do trabalho e, consequentemente, o agravo das condições de vida dos trabalhadores. Enfrenta processos e dinâmicas que trazem para a profissão novas temáticas, novos (e os de sempre) sujeitos sociais, por meio de questões vinculadas ao desemprego estrutural, trabalho infantil, violência doméstica, discriminação de gênero e etnia, entre outros (Yazbek, Raichelis e Martinelli, 2008).

Diante disso, torna-se um desafio decifrar as lógicas do capitalismo contemporâneo, sobretudo no que se refere às mudanças no mundo do trabalho e à desestruturação dos sistemas de proteção social e das políticas sociais de forma ampliada. Lógicas capazes de despolitizar a questão social, além de reiterar a desigualdade, na medida em que também penaliza os trabalhadores por sua condição de precariedade na sociedade atual (Iamamoto, 2008; Yazbek, 2009). 
No entanto, o Serviço Social, a partir do avanço na produção do conhecimento, da busca de romper com seu histórico conservadorismo, dos debates sobre a formação profissional, das revisões curriculares, entre outros elementos, constrói um projeto profissional ${ }^{2}$ (a partir do movimento de reconceituação) com princípios que vão nortear a materialização de suas ações.

Os princípios éticos norteadores do projeto possuem como questão central a liberdade do ser social. Esta que é compromissada com valores que dizem respeito a determinadas projeções sociais e que tem protagonistas histórico-sociais efetivos.

Segundo Barroco (2009), a efetivação desses princípios remete a luta, no campo democrático popular, pela construção de uma nova ordem societária. Princípios que, ao se materializarem no cotidiano, indicam um novo modo de operar o trabalho profissional, balizando as expressões da categoria profissional de forma geral e no que se refere às condições e relações de trabalho.

Nesse cenário, Nogueira (2010) ressalta que a Abess, em sua gestão 1992-94, inicia um novo processo de revisão curricular a partir do "Relatório-síntese dos impasses e tensões da formação profissional", produzidos após a realização de várias oficinas regionais concluídas em 1995. Esse relatório aponta equívocos na implementação curricular que impactaram

a produção e a transmissão de conhecimentos, como o ecletismo teórico; o formalismo na apropriação da teoria crítica, a superficialidade na apropriação dos paradigmas e a distância entre apreensão da realidade e a intervenção. (Nogueira, 2010, p. 6)

Após a revisão, foi estruturada uma nova proposta curricular aprovada em 1996 pela Abess. Essa proposta teve por base os seguintes pressupostos: 1) Serviço Social como profissão interventiva no âmbito da questão social no capitalismo monopolista; 2) A necessidade de compreensão dos processos sociais e de uma perspectiva teórico-metodológica para isso. A partir dessa proposta, são destacados pela Abess (1996) três princípios básicos para avaliação da pesquisa:

- Rigoroso trato teórico, histórico e metodológico da realidade social e do Serviço Social que possibilite a compreensão dos problemas e desafios com os quais o profissional se defronta no universo da produção e reprodução da vida social;

2. Projeto pautado na lei de regulamentação da profissão, no código de ética profissional e nas diretrizes curriculares. 
- Adoção de uma teoria social crítica que possibilite a apreensão da totalidade social em suas dimensões de universalidade, particularidade e singularidade;

- Estabelecimento das dimensões investigativas e interventivas como princípios formativos e condição central da formação profissional e da relação teoria e realidade.

É necessário sinalizar que as diretrizes curriculares indicam, através dos princípios de orientação da ação profissional, a necessidade de capacitação teórico-metodológica, ético-política e técnico-operativa nas seguintes direções (Abess, 1996):

- apreensão crítica do processo histórico,

- a investigação sobre a nossa formação histórica e os processos sociais contemporâneos vivenciados pela sociedade brasileira,

- a apreensão do significado social da profissão, desvelando as possibilidades de ação contidas na realidade, apreensão das demandas - consolidadas e emergentes - visando formular respostas profissionais,

- exercício profissional cumprindo as competências e atribuições previstas na legislação profissional em vigor.

A partir desses princípios, é possível destacar a relevância da pesquisa em Serviço Social. Na mesma proposta é apresentado o seguinte conteúdo:

Natureza, método e processo de construção do conhecimento: o debate teórico-metodológico. A elaboração e análise de indicadores socioeconômicos. A investigação como dimensão constitutiva do trabalho do assistente social e como subsídio para a produção do conhecimento sobre processos sociais e reconstrução do objeto da ação profissional. (Abess, 1997, p. 71)

A avaliação encaminhada pela Abepss em 2007 e concluída em 2008 apresenta significativas contribuições. De acordo com Abreu (2008), é possível visualizar três tendências: 1) Ênfase nos aspectos técnico-operativos da disciplina, conforme ementa do MEC; 2) Abordagem relativa aos aspectos teórico-metodológicos, particularizando o debate em torno da produção do conhecimento no Serviço Social; 3) Inclusão dos aspectos anteriores em articulação a atividades práticas de exercício da pesquisa e o desenvolvimento do espírito investigativo.

Diante disso, concordamos com Abreu (2008) e Nogueira (2010) de que é reposto nesse currículo a debilidade avaliada no de 1982: o alheamento entre pes- 
quisa e ação profissional. Além disso, é possível apresentar outros aspectos pouco problematizados em relação à pesquisa na formação profissional, como: o fato de sua construção ser a partir da curiosidade científica em relação ao já vivido na busca de ampliar o leque de questões teóricas mais abstratas; a forma como o método crítico vem sendo apropriado e usado como ferramenta analítica; a banalização da pesquisa; e a dificuldade de articulação entre a disciplina de pesquisa e as demais disciplinas no curso de graduação em Serviço Social (Nogueira, 2010).

Por outro lado, outras questões se tornam relevantes nesse processo, como por exemplo, o fato de a universidade ser encarada como um grande negócio na atualidade, havendo uma descaracterização de seus princípios mais caros como a autonomia e a indissociabilidade entre ensino, pesquisa e extensão, fundamentais à universidade pública. Nesse contexto, e considerando essas questões, torna-se fundamental uma futura reflexão em relação ao papel e à importância da pesquisa, particularmente da pesquisa social, na universidade pública (Brandão, 2010). Ou seja, esta reflexão deve considerar o tipo de formação que está sendo pautada nas universidades diante da desvalorização e da descaracterização da pesquisa.

No caso do Serviço Social, esse debate é fundamental, visto que algumas indicações profissionais atuais caracterizam-se por vincular a pesquisa à ação do assistente social. No entanto, se durante o processo de formação profissional o discente não tem acesso a disciplinas de pesquisa que trabalhem articuladas a outras disciplinas do currículo e vice-versa; se essas disciplinas não abordam a particularidade da produção do conhecimento no Serviço Social articulando teoria e prática de forma unitária; se o discente não tem oportunidade de participar de projetos e grupos de pesquisa, além de não ter acesso a bolsas de iniciação científica por exemplo, torna-se complexo plasmar a pesquisa na prática profissional, pois além das naturais dificuldades vinculadas à operacionalização da proposta de pesquisa na prática profissional, existem questões (da formação profissional) que vinculam a falta de bagagem teórica, metodológica, ética e política para que essa atividade seja desenvolvida com qualidade pela universidade e rompa os muros acadêmicos.

$\mathrm{Na}$ sociedade atual, esses processos têm se tornado ainda mais contraditórios com o aumento dos cursos de graduação à distância e dos cursos de Serviço Social particulares, em que princípios ${ }^{3}$ (da universidade) não são incorporados no proces-

3. De acordo com Faria (2005, p. 22), podemos destacar os seguintes princípios da universidade: "indissociabilidade entre a produção e a transmissão do conhecimento; o da autonomia plena com relação 
so de formação profissional, pois o vínculo dessas instituições é exclusivo para o mercado.

Diante destas reflexões, construímos a seguinte questão: que elementos subsidiam a pesquisa no exercício do Serviço Social na contemporaneidade? É acerca desta questão que o próximo item será desenvolvido.

\section{Desdobramentos da pesquisa para o exercício da profissão}

Desigualdade, pobreza, desmonte das políticas de proteção social, envelhecimento populacional, famílias chefiadas por mulheres, trabalho infantil são alguns dos traços que marcam a sociedade contemporânea (Yazbek, Raichelis e Martinelli, 2008).

Nesse cenário, é possível identificar que análises referenciam a chamada "mundialização do capital" e as discussões relacionadas ao "capital fetiche" (Iamamoto, 2007) como alguns dos elementos impulsionadores da realidade brasileira atual. Neste caso, o Estado, ao ser "capturado" pelas políticas econômicas globais, com base no ideário neoliberal, desenvolve um processo de "contrarreforma", preconizado por uma mínima atuação na área social (Yazbek, Raichellis e Martinelli, 2008).

Assim, há o desmonte do Sistema de Seguridade Social brasileiro, e as políticas sociais de maneira geral se tornam cada vez mais focalizadas, seletivas, fragmentadas e direcionadas aos miseráveis, que são incluídos através do "mérito da necessidade" (Sposati, 1993).

Nessa lógica, há o aumento das parcerias entre público-privado e o crescimento do "terceiro setor", vinculando a cidadania ao mercado e desenvolvendo traços conservadores em relação à "questão social" e aos movimentos sociais, na medida em que se constrói um trato refilantropizador e despolitizador da questão social (com claros chamamentos à sociedade civil), numa perspectiva moralizadora.

As repercussões desses rearranjos políticos, econômicos e sociais vão incidir diretamente na vida dos trabalhadores. Segundo Antunes (2005), nunca se viu um quantitativo de desemprego tão elevado, além do crescimento da informalidade, da

\footnotetext{
aos seus órgãos mantenedores; o da qualidade acadêmica; o da manutenção e da ampliação das formas democráticas de ação; o de atendimento das necessidades da sociedade por meio da defesa da pluralidade do conhecimento e da cidadania".
} 
precarização do trabalho, da subcontratação, da terceirização, entre outros fatores, que criam novos padrões de discriminação (por sexo, idade, etnia) e contribuem para que haja substituição (não eliminação) do trabalho vivo pelo "trabalho morto" (nos termos de Marx). Por outro lado, Iamamoto (2008) ressalta que há o objetivo de "cooptar" os trabalhadores como parceiros do grande capital. A esse respeito, o mesmo Antunes (2005) destaca que há a busca do envolvimento subjetivo e social do trabalhador pelas instituições empregadoras.

Esse processo contribui para que as políticas sejam trabalhadas de maneira focada no combate à pobreza, além de, segundo Iamamoto (2008), redimensionar a "questão social" na contemporaneidade. Para a autora, a "questão social" é mais que pobreza e desigualdade, expressa a banalização do humano, resultante da indiferença frente à esfera da necessidade das grandes maiorias e dos direitos a ela atinentes.

Essa conjuntura vai influenciar diretamente o Serviço Social. Nesse sentido, Iamamoto (2007) ressalta a necessidade de um novo perfil profissional que tenha por base competência crítica. Esse profissional deve ser capaz de pensar, analisar, pesquisar e decifrar a realidade a partir de uma atitude investigativa que deve perpassar o seu cotidiano. Além disso, deve ser capaz de analisar os processos sociais, entendendo o presente e contribuindo para a construção do futuro.

Essas características são fundamentais para analisar, compreender e intervir na realidade social. Visto que o próprio assistente social vai sofrer as incidências dessas transformações societárias, seja no que se refere às suas condições e relações de trabalho, seja em relação ao tipo de demanda e as possibilidades de respostas profissionais.

A esse respeito, é possível destacar, de acordo com Iamamoto (2008) e Ortiz (2010) que o debate em torno da condição de assalariamento do assistente social e a natureza das requisições profissionais tem sido preocupação por parte da categoria, visto que o exercício da profissão é tensionado pela compra e venda de sua força de trabalho especializada, enquanto trabalhador assalariado, determinante fundamental na autonomia profissional.

Esta condição envolve a incorporação de parâmetros institucionais e trabalhistas que regulam as relações de trabalho, consubstanciadas no contrato de trabalho, estabelecendo as condições em que o mesmo se realiza. Oferecem os recursos indispensáveis a sua objetivação e recortam as expressões da "questão social" que podem se tornar matéria-prima do trabalho profissional. 
Assim, o profissional sofre dois vetores de demandas na realização de seu trabalho: 1) o vetor institucional a partir das exigências impostas pelos distintos empregadores; e 2) as necessidades sociais dos cidadãos que se tornam demandas dos usuários. É nesse terreno denso de tensões e contradições sociais que se situa o protagonismo profissional (Iamamoto, 2007).

Esse processo atual requer do profissional competência teórico-metodológica para leitura da realidade, bem como a incorporação da pesquisa e do conhecimento do modo de vida, de trabalho e expressões culturais desses sujeitos sociais, como requisitos essenciais do desempenho profissional, além de sensibilidade e vontade política que movem a ação.

Nesse caso, é perceptível que a pesquisa se torna um importante instrumento para a prática profissional ${ }^{4}$ (Iamamoto, 2008; Neto, 1990). No entanto, é possível identificar, não raras vezes, que esse discurso pode não alcançar a prática. ${ }^{5}$ As justificativas por parte dos assistentes sociais são muitas: falta de tempo, excesso de atribuições, pouca disponibilidade de pessoal, ausência de recursos... Mesmo com essas restrições, nos deparamos com situações em que a pesquisa é incorporada ao trabalho do profissional, sobretudo por motivo de cursos de especializações. Nesses casos, é vinculada a ideia de que a pesquisa está estritamente relacionada a normas, prazos e obrigação a ser cumprida, aprisionando uma prática que deveria ousar, desafiar, investigar e gerar prazer com as novas descobertas e possibilidades de ação (Moraes, Juncá e Santos, 2010).

Não há aqui a defesa da banalização ou o enfraquecimento do rigor e critérios científicos. Há reconhecimento e valorização da relevância de projetos desenvolvidos pelas universidades. Porém é necessário refletir de maneira mais aprofundada acerca do sentido e do significado da prática da pesquisa para o cotidiano do assistente social e, além disso, é necessário ressaltar que (enquanto aspecto inter-

4. Para Baptista (2009, p. 18) a prática profissional situada no âmbito das relações sociais concretas de cada sociedade, em sua configuração, sintetiza o seu movimento histórico. Não se confunde com outras práticas, apesar de constituir uma dimensão historicamente determinada da prática social que se manifesta concretamente em uma situação social específica (sendo expressão de classe).

5. Este estudo apresenta uma preocupação com a prática ancorado na abordagem de Battini (2009, p. 74): A preocupação com a prática tem duplo caráter: de investigação e de intervenção. "Esse duplo caráter exige do assistente social uma postura metodológica que lhe garanta unidade teoria/prática; que lhe conceda oportunidades de ampliação do limite dado; que lhe propicie clareza para sua introdução no concreto real, no sentido de melhor explicar as interconexões, criando as condições de apropriação teórico-prática na particularidade dos fenômenos sociais". 
ligado à pesquisa) a prática não sustentada pela postura investigativa ${ }^{6}$ se torna limitada no que se refere ao pensar e ao agir, tendendo a confirmar a prática constituída, sem criar condições para novas formas de apreender e agir sobre o objeto profissional, de maneira a reificar e confirmar o vigente (Battini, 2009).

Assim, há aqui a defesa por uma prática que deve ser "construída artesanalmente" (Mills, 1982, p. 211) desenhada de maneira apaixonada, vibrante e desafiadora.

Prática com fome de descobertas, combinando razão e sensibilidade, rigor e criatividade, ciência e arte, conhecimento e ação. Prática que comemora os "achados" do processo de investigação, mas que com ponderação e humildade desconfia destes "achados" e quer avançar sempre mais, valorizando os sujeitos com os quais se relaciona. (Moraes, Juncá e Santos, 2010, p. 434)

Se a pesquisa deve ser encarada com gosto (Eco, 1977), muitas questões precisam ser enfrentadas em sua prática no Serviço Social, já que é necessário garantir a unidade entre o saber e o fazer, o saber fazer e o refazer, ancorados na compreensão do tipo de sociedade que se almeja.

Ao se perguntar “pesquisa: para quê?" Rubem Alves (1989) problematiza a função social do conhecimento produzido e o resultado social das investigações dos pesquisadores. Isto é, a quem se destina este conhecimento e de que maneira esses sujeitos podem se apropriar do mesmo.

Outros fatores a considerar é o que Cynthia Crossen (1996) e Aquino (2001) problematizam: o uso indiscrimado do termo pesquisa, o modo como são produzidos os dados e o uso que se faz dos mesmos. Ou seja, qual a finalidade de produção de tantos dados? Como eles são produzidos?

Ao retomar o cotidiano profissional do Serviço Social, é possível perceber uma gama de informações a respeito dos usuários: sexo, ocupação, composições familiares, condições habitacionais, dentre outros. É certo que tais informações são relevantes para a condução das atividades profissionais, no entanto, há necessidade de problematizá-las (articulando suas dimensões singulares/particulares ao universal), buscando compreender suas causas e possíveis significados, ancorados na busca de alternativas à realidade dos mesmos, pautadas no projeto ético-político profissional.

6. De acordo com a Abess (1996) a postura investigativa é um suposto para sistematização teórica e prática do exercício profissional, para definição de estratégias e instrumental técnico que busquem enfrentar a desigualdade social. 
Isto significa que é preciso pensar na ação política que tal processo pode envolver, no protagonismo dos sujeitos, pesquisadores e pesquisados, em que "o desafio é tecer uma rede interpretativa onde o fenômeno estudado possa ser compreendido como parte de um universo e, ao mesmo tempo, um universo à parte" (Barbiani, 2004, p. 1).

Admite-se aqui o movimento que Morim (2001) ressalta: ordem-desordem-organização, além do que Barbiani (2004) chama de a importância do entrecruzamento de múltiplas vozes, temporalidades e movimentos. Isto porque o conhecimento se configura do singular ao particular, ${ }^{7}$ mediado pelo universal, imergindo numa realidade que se movimenta constantemente não possibilitando ter consciência, ao certo, de onde chegará.

Com tais considerações, queremos reforçar nossa concepção de pesquisa, onde há um lugar garantido para a indagação inacabada, para movimentos de aproximação sucessiva, onde teoria e dados dialogam, permanentemente, enfatizando, como Demo (1991), que não se trata apenas de busca de conhecimento, mas também de um fenômeno político. Cabe, portanto, reconhecer que estamos diante de um processo complexo, a ser conduzido de forma cuidadosa e criteriosa, comportando não só um olhar que indaga e quer saber, mas também aquele que se compromete e quer fazer algo, o que no caso do Serviço Social está afinado com a ultrapassagem do imediatismo e sacralização do exercício profissional, remetendo ao desafio de operacionalizar seu projeto ético-político. (Moraes, Juncá e Santos, 2010, p. 246-47)

Diante dessas afirmações, é possível questionar: de que maneira, a possibilidade do desenvolvimento da pesquisa contribui para o "estranhamento" no processo de produção do conhecimento? O que o profissional de Serviço Social vê e o que deixa de ver em seu cotidiano profissional? Que dimensões o "ver" deve assumir na prática profissional do assistente social?

Essas indagações têm por base o poema de Otto Lara Resende que ressalta: "De tanto ver, a gente banaliza o olhar - vê... não — vendo". Este poema, articulado às nossas reflexões, nos possibilita afirmar a construção de um desafio concernente à prática profissional do assistente social, desafio que nem sempre se assume, por acreditar que a experiência profissional reiterada durante anos é capaz de

7. A compreensão de singularidade e particularidade aqui trabalhadas consideram às discussões de Barroco (2009) em relação aos "Fundamentos éticos do Serviço Social". 
proporcionar respostas à realidade trabalhada. A relevância da experiência profissional é inquestionável. No entanto, ela também pode "cegar", sendo capaz de dificultar análises mais críticas, limitando a reconstrução permanente da profissão.

No contexto da pesquisa, esse desafio deve ter por base a afirmação de Martinelli (2005, p. 10): "pesquisar na perspectiva qualitativa, é sempre em articulação com a pesquisa quantitativa", ou seja, "contemplar de modo pacientemente impaciente o que se pretende pesquisar", exercitando "o olhar rigoroso, crítico, atento", buscando "o desvendamento crítico da realidade em análise, com vistas a uma intervenção mais qualificada".

Esta afirmação é corroborada por Bourguignon (2007) e Marsiglia (2006) ao afirmarem a pesquisa como instrumento estratégico na atuação profissional. Assim, ela se apresenta como possibilidade de objetivação da prática profissional e desafio para os profissionais que pretendem ser críticos e propositivos (Bouguignon, 2007). Ou seja, no caso do Serviço Social, um dos desafios que se coloca no terreno da pesquisa refere-se ao fato de "alimentar práticas profissionais comprometidas com processos emancipatórios" (Bourguignon, 2008, p. 302-303).

Para além desses desafios da pesquisa no campo do Serviço Social, Bourguignon (2008) indica que a centralidade dos sujeitos que participam de suas pesquisas enquanto condição ontológica tem se apresentado como uma lacuna. Nesses casos, é necessário, por meio da pesquisa, desenvolver análises que permitam dar maior visibilidade aos usuários, valorizando sua experiência, conhecimento, história e vivência cotidiana. Essas análises devem situá-los no contexto sócio-histórico, articulado criticamente à dinamicidade da realidade.

No entanto, se essas concepções têm se tornado hegemônicas no debate acadêmico, deve-se também tentar avaliar como elas têm sido correlacionadas à prática profissional do assistente social. Há indicativos de que por vezes esse discurso, não tem atingido as ações profissionais de maneira veemente. Todavia, devem ser analisados quais são os fatores que estão colaborando para que ocorra tal acontecimento, se assim for identificado.

\section{Considerações finais}

Ao identificar a trajetória da pesquisa como tema e disciplina na formação profissional do Serviço Social, pesaram no horizonte dessa discussão imensas dú- 
vidas e poucas certezas sobre como encaminhar a sua articulação com a dimensão interventiva.

Visto que, de maneira geral, são precárias as condições objetivas para o enfrentamento desses desafios (que vinculam a pesquisa na formação e exercício da profissão) e o cumprimento dessas exigências.

Identificamos desafios referentes às unidades de ensino em que se encontram, segundo Yazbek, Raichelis e Martinelli (2008): 1) A mercantilização e precarização do ensino no âmbito da formação profissional, que pode atingir a identidade do Serviço Social, uma vez que há dificuldades concretas de se formar profissionais competentes e críticos neste quadro; 2) $\mathrm{O}$ ensino à distância que introduz mudanças drásticas e alteram o perfil da formação profissional no Brasil.

Isso significa que não é possível pensar a pesquisa (enquanto tema e disciplina) sem se preocupar, antes, com o real significado da profissão que tem razão de ser na intervenção. Isto é, essa temática exige que se desenvolva uma "viagem de volta", compreendendo os principais determinantes (sociais, econômicos, políticos, culturais) que contribuíram para a construção do Serviço Social, suas dimensões teóricas, metodológicas, éticas, políticas, técnicas e operativas, bem como os sentidos da proposta da pesquisa na formação e prática profissional.

Neste caso, é fundamental fortalecer a reflexão referente ao papel e a importância da pesquisa na Universidade pública na atualidade. Isto é, que tipo de formação está sendo pautada na universidade diante da desvalorização e descaracterização dos princípios da Universidade pública, bem como da própria pesquisa.

Por outro lado, é necessário que o assistente social desenvolva competência crítica para compreender a realidade e, neste caso, a pesquisa se apresenta como instrumento estratégico na atuação profissional, na medida em que pode garantir a unidade entre o saber e o fazer, ancorada em que tipo de sociedade que se almeja (ação política).

Diante disso, vale levantar as seguintes questões para o desenvolvimento de eventuais estudos que tenham por objetivo mapear o "estado da arte" na pesquisa no Serviço Social.

- Historicamente, quais as dimensões assumidas pela pesquisa na formação profissional em Serviço Social? Qual o contexto sócio-histórico de seu surgimento e desenvolvimento?

- De que maneira a pesquisa é pensada e trabalhada pela graduação em Serviço Social na atualidade? 
- Como a dicotomia ${ }^{8}$ entre "prática profissional versus pesquisa científica" é enfrentada na atualidade por parte do Serviço Social?

- Quais os atuais sentidos da pesquisa para a prática profissional do assistente social?

- A importância da pesquisa propagada no discurso acadêmico tem sido contemplada na prática profissional dos assistentes sociais?

- Quais são as concepções dos assistentes sociais acerca de pesquisa?

- A pesquisa tem sido operacionalizada pelos assistentes sociais em seu trabalho profissional? Caso sim, que dimensões ela vem assumindo em sua prática profissional?

- A prática da pesquisa do Serviço Social tem se preocupado com a centralidade do sujeito, possibilitando-lhe maior visibilidade, através da compreensão de sua experiência e conhecimento? ${ }^{9}$

- Que possibilidades metodológicas podem ser pensadas e sugeridas para a pesquisa na prática profissional do assistente social?

Neste caso, é necessário identificar, extrair e analisar as incidências da dinâmica societária (relações e contradições sociais) "nos fundamentos e processamento de trabalho profissional", particularizando a pesquisa e produção de conhecimento. Estas análises possibilitarão retomar, "sob novas luzes, o Serviço Social" (Iamamoto, 2008, p. 44). Isto é, há aqui a indicação de se analisar de maneira aprofundada (em futuros estudos) a produção do conhecimento em Serviço Social e seus vínculos com a formação e prática profissional, sob uma perspectiva crítica, histórica e atual.

\section{Recebido em 11/6/2012 - Aprovado em 11/3/2013}

8. A identificação dessa dicotomia é debatida por Bourguignon em A particularidade histórica da pesquisa no Serviço Social, 2007.

9. A esse respeito, Bourguignon (2007) ressalta que o grande desafio para o pesquisador assistente social, que se preocupa com a centralidade do sujeito enquanto condição ontológica e não como estratégia metodológica de pesquisa, é possibilitar através da pesquisa, maior visibilidade ao sujeito, a sua experiência e ao seu conhecimento, cuja natureza, se desvendada, poderá permitir desenvolver práticas cada vez mais comprometidas ética e politicamente com a realidade, buscando no coletivo e na troca de saberes alternativas de superação das condições de privação e exclusão social. 


\section{Referências bibliográficas}

ABEPSS. Diretrizes gerais para o curso de Serviço Social - 1996. Disponível em: < http:// www.abepss.org.br/briefing/graduacao/Lei_de_Diretrizes_Curriculares $>$. Acesso em: 11 nov. 2011.

ABESS/CEDEPSS. Formação profissional: trajetórias e desafios. Cadernos Abess, São Paulo, Cortez, n. 7, 1997.

. Relatório-síntese dos impasses e tensões da formação profissional. Digital, 2005.

ABREU, M. M. A pesquisa. In: ABEPSS. Relatório final da pesquisa avaliativa da implementação das diretrizes curriculares do curso de Serviço Social. CD-ROM. São Luís, out. 2008.

ALVES, R. Filosofia da ciência: introdução ao jogo e suas regras. São Paulo: Ars Poética, 1996.

Pesquisa: para quê? [1989]. Mimeo.

ANTUNES, Ricardo. O caracol e sua concha: ensaios sobre a nova morfologia do trabalho. São Paulo, Boitempo, 2005.

AQUINO, E. de F. Um velho Brasil estatístico e o novo demografismo social. Aliança em Revista, Brasília, v. 2, n. 6, p. 12-13, jun./jul. 2001.

BAPTISTA, M. V. A prática profissional do assistente social: teoria, ação, construção de conhecimento. São Paulo: Veras, 2009.

BARBIANI, R. Sobre o ato de conhecer e o conhecer em ato... onde está o sujeito da frase? In: ENCONTRO NACIONAL DE PESQUISADORES EM SERVIÇO SOCIAL, 9., Anais..., Porto Alegre: Abepess, 2004. [CD-ROM.]

BARROCO, M. L. Reflexões sobre ética, pesquisa e Serviço Social. Temporalis, Recife, Abepss, v. 5, n. 9, p. 103-116, jan./jun. 2005.

BARROCO, M. L. S. Fundamentos éticos do Serviço Social. In: . Serviço Social: direitos e competências profissionais. Brasília: CFESS/Abepss, 2009.

BATTINI, O. Atitude investigativa e prática profissional. In: ; BAPTISTA, Myrian Veras (Orgs.). A prática profissional do assistente social: teoria, ação, construção de conhecimento. São Paulo: Veras Editora, 2009.

BOURGUIGNON, J. A. A particularidade histórica da pesquisa no Serviço Social. Katálysis, Florianópolis, v. 10, 2007. 
BOURGUIGNON, J. A. A centralidade ocupada pelos sujeitos que participam das pesquisas do Serviço Social. Textos e Contextos, Porto Alegre, v. 7 n. 2, p. 302-312, jul./dez. 2008.

BRANDÃO, S. M. S. O. As contribuições da pesquisa para o processo de formação profissional no Curso de Serviço Social da UFMA. In: ENCONTRO NACIONAL DE PESQUISADORES EM SERVIÇO SOCIAL, 12., Anais..., Rio de Janeiro, dez. 2010.

BRASIL. Constituição da República Federativa do Brasil: promulgada em 5 de outubro de 1988. Brasília: Senado Federal, 1988.

BRAVO, M. I. S.; MATOS, M. C. Reforma sanitária e projeto ético-político do Serviço Social: elementos para o debate. In: et al. (Orgs.). Saúde e Serviço Social. São Paulo: Cortez; Rio de Janeiro: UERJ, 2004.

CARDOSO, F. G. A pesquisa na formação profissional do assistente social: algumas exigências e desafios. Caderno Abess, Associação Brasileira de Ensino de Serviço Social. Diretrizes Curriculares e Pesquisa em Serviço Social, São Paulo, n. 8, 1998.

CONSELHO FEDERAL DE SERVIÇO SOCIAL. Parâmetros para atuação de assistentes sociais na saúde. Grupo de Trabalho Serviço Social na Saúde. Brasília, Cefess, nov. 2009.

CROSSEN, C. O fundo falso das pesquisas: a ciência das verdades torcidas. Rio de Janeiro: Revan, 1996.

DEMO, P. Pesquisa: princípio científico e educativo. São Paulo: Cortez, 1991.

ECO, U. Como se faz uma tese. 14. ed. São Paulo: Perspectiva, 1977.

FARIA, J. H. de. Universidade, produção científica e aderência social: a indissociabilidade e contra-reforma do ensino superior. Universidade e Sociedade, Brasília, ano 15, n. 35, p. 13-33, fev. 2005.

FAUSTO NETO, A. M. Q. Produção científica e formação profissional — os paradigmas do conhecimento e seu rebatimento no cotidiano do ensino, da pesquisa e do exercício profissional. Cadernos Abess, Produção Científica e Formação Profissional. São Paulo, n. $6,1993$.

FRAGA, C. K. A atitude investigativa no trabalho do assistente social. Serviço Social \& Sociedade, São Paulo, n. 101, p. 40-64, jan./mar. 2010.

IAMAMOTO, M. V. Renovação e conservadorismo no Serviço Social. 8. ed. São Paulo: Cortez, 2007.

Ensino e pesquisa no Serviço Social: desafios na construção de um projeto e formação profissional. Caderno Abess, Associação Brasileira de Ensino de Serviço Social. Diretrizes Curriculares e Pesquisa em Serviço Social, São Paulo, n. 8, 1998. 
IAMAMOTO, M. V. Serviço Social em tempo de capital fetiche: capital financeiro, trabalho e questão social. 2 ed. São Paulo: Cortez, 2008.

; CARVAlHO, R. Relações Sociais e Serviço Social no Brasil. Esboço de uma interpretação histórico metodológica. 1. ed. São Paulo, Cortez/Celats, 1982.

IANNI, O. Enigmas da modernidade: mundo. Rio de Janeiro: Civilização Brasileira, 2000.

JUNCÁ, D. C. de M. A teoria é uma coisa, mas a prática pode não ser outra. O Social em Questão, n. 9, p. 10-22, $1^{\circ}$ set. 2009.

KAMEYAMA, N. A trajetória da produção de conhecimentos em Serviço Social: avanços e tendências (1995 a 1997). Caderno Abess, Associação Brasileira de Ensino de Serviço Social. Diretrizes Curriculares e Pesquisa em Serviço Social, São Paulo, n. 8, 1998.

MARSIGLIA, R. M. G. Orientações Básicas para a Pesquisa. In: et al. (Orgs.).

Serviço Social e saúde: formação e trabalho profissional. São Paulo: Cortez, 2006. p. 383-98.

MARTINELLI, M. L. Pesquisa qualitativa: elementos conceituais e teórico-metodológicos. Encontro de pesquisadores do Instituto de Ciências da Sociedade e Desenvolvimento Regional. Campos dos Goytacazes, n. 1, p. 8-15, out. 2005.

. Serviço Social: identidade e alienação. 11. ed. São Paulo: Cortez, 2009.

MATOS, M. C. O debate do serviço social na saúde na década de 90. Serviço Social \& Sociedade, São Paulo, n. 74, 2003.

MILLS, C. W. A imaginação sociológica. 6. ed. Rio de Janeiro: Zahar, 1982.

MORAES, C. A. de S. et al. Para quê? Para quem? Alguns desafios do cotidiano da pesquisa em serviço social. Serviço Social \& Sociedade, n. 109, p. 433-52, jul./set. 2010.

et al. Quem fomos? Quem somos? In: SEMINÁRIO DE PESQUISA DO INSTITUTO DE CIÊNCIAS DA SOCIEDADE E DESENVOLVIMENTO REGIONAL, 4., Anais... Uma análise comparativa entre estudantes de Serviço Social do ano 2000 e 2010 da Universidade Federal Fluminense — UFF/Campos dos Goytacazes/Rio de Janeiro, Brasil, mar. 2011.

MORIN, E. A religação dos saberes: o desafio do século XXI. Rio de Janeiro: Bertrand Brasil, 2001.

MOTA, A. E. Reestruturação produtiva e Serviço Social. Praia Vermelha, Rio de Janeiro, v. 1, n. 2 , p. $33-48,1^{\circ}$ sem. 1999.

NETTO, J. P. Democracia e transição socialista: escritos de teoria e política. Belo Horizonte: Oficina de Livros, 1990. 
NETTO, J. P. A construção do projeto ético político do Serviço Social frente á crise contemporânea. In: CFESS/ABEPSS; CEAD/UnB (Orgs.). Crise contemporânea, questão social e Serviço Social: capacitação em Serviço Social e política social. Brasília: Cead/UnB, 1999.

. Ditadura e Serviço Social: uma análise do Serviço Social no Brasil pós-64. São Paulo: Cortez, 2001.

NOGUEIRA, V. M. R. Elementos para pensar a pesquisa como princípio formativo em Serviço Social. In: ENCONTRO NACIONAL DE PESQUISADORES EM SERVIÇO SOCIAL, 12., Anais..., Rio de Janeiro, dez. 2010.

ORTIZ, F. G. O Serviço Social no Brasil: os fundamentos de sua imagem e da autoimagem de seus agentes. Rio de Janeiro: E-Papers, 2010.

PASTOR, M.; MARQUES, M. I. B. Pesquisa na formação e atuação do assistente social. In: ENCONTRO NACIONAL DE PESQUISADORES EM SERVIÇO SOCIAL,12., Anais..., Rio de Janeiro, dez. 2010.

SETUBAL, A. A particularidade histórica da pesquisa no Serviço Social. Katálisis, Florianópolis, v. 10, número especial, p. 64-72, 2007.

SPOSATI, A. Pesquisa e produção de conhecimento no campo do Serviço Social. Katálysis, Florianópolis, v. 10, número especial, 2007.

VASCONCELOS, A. M. de. Serviço Social e prática reflexiva. Em Pauta, Rio de Janeiro, n. 10, 1993.

YAZBEK, M. C. Classes subalternas e assistência social. 7. ed. São Paulo: Cortez, 2009. ; RAICHELIS, R.; MARTINELLI, M. L. O Serviço Social Brasileiro em Movimento: fortalecendo a profissão na defesa de direitos. Serviço Social \& Sociedade, São Paulo, n. $95,2008$. 